\title{
Caterina Mauri* and Andrea Sansò Heterogeneous sets: a diachronic typology of associative and similative plurals
}

\author{
https://doi.org/10.1515/lingty-2021-2072
}

Received October 4, 2019; accepted October 31, 2020;

published online February 15, 2021

\begin{abstract}
This paper provides a diachronic typology of what we call 'heterogeneous plurals', an overarching term comprising associative plurals (expressions meaning $\mathrm{X}_{\text {[person] }}$ \& company) and similative plurals (expressions meaning $\mathrm{X}$ and similar entities). Based on a 110-language sample, we identify the most recurrent sources of these two types of plurals by means of various types of evidence (homophony/identity, internal reconstruction, comparison with cognate languages). The two types of plurals develop out of different source types: while the sources of associative plurals include elements that work as set constructors (plural anaphoric elements, plural possessives, names meaning 'group'), those of similative plurals comprise elements with vague reference such as interrogative/indefinite items or uncertainty markers. There are also a few source types that may develop into both associative and similative plurals, such as connectives ('and/with') and universal quantifiers ('every/all'). The differences in the diachronic pathways leading to the two types of plurals are explained in terms of the different referential properties of the nominal bases from which they are formed (proper names/kin terms vs. common nouns), but also taking into
\end{abstract}

This article is the result of joint work. Caterina Mauri is responsible for Sections 1, 2, 4.2, and 5 , while Andrea Sansò is responsible for Sections 3, 4.1, and 6. We wish to thank Michael Daniel, an anonymous referee and the editorial board of Linguistic Typology for useful comments on an earlier draft of the article. This research was developed within the SIR project 'LEAdhoC - Linguistic expression of ad hoc categories' (prot. n. RBSI14IIG0), funded by the Italian Ministry of Education, Universities and Research and coordinated by Caterina Mauri. The usual disclaimers apply.

*Corresponding author: Caterina Mauri [Kate'rina' mawri], Dipartimento di Lingue, Letterature e Culture Moderne, Università di Bologna - Alma Mater Studiorum, Via Cartoleria 5, 40124, Bologna, Italy, E-mail: caterina.mauri@unibo.it

Andrea Sansò [an'drea san'sJ], Dipartimento di Scienze Umane e dell'Innovazione per il Territorio, Università dell'Insubria, Via S. Abbondio 12, 22100, Como, Italy, E-mail: andrea.sanso@uninsubria.it 
account the typical discourse contexts in which the two types of plurals are employed.

Keywords: associative plural, associativity, diachronic typology, heterogeneous plurals, similarity, similative plural

\section{Introduction}

This paper aims to provide a diachronic typology of two constructions that are generally labeled associative and similative plurals, the former typically limited to proper names and kin terms (' $\mathrm{X}$ and company/friends/family'), the latter generally possible with animate and inanimate referents (' $\mathrm{X}$ and similar entities'). These two construction types have been described and discussed mainly in terms of their difference with respect to ordinary plurals (Cinque 2018; Corbett 2000: 107-110; Corbett and Mithun 1996; Daniel and Moravcsik 2013; Moravcsik 2003 among others), but little, if anything, has been said about the diachronic paths leading to their emergence.

Based on a 110-language sample, we discuss to what extent the differences observed between the diachronic sources for associative and similative plurals reflect the semantic differences between the two typical referent types that form these two constructions, namely proper names/kin terms on the one hand, and common nouns on the other. The analysis of the observed synchronic and diachronic variation will allow us to focus on differences and commonalities between the two constructions, tackling the question of whether they can be considered as two facets of the same phenomenon.

After providing definitions of the two construction types (Section 2), we will describe the sample on which this analysis is based and the method and aims of diachronic typology (Section 3). We will then separately discuss the attested diachronic sources for associative plurals (Section 4.1) and similative plurals (Section 4.2), providing evidence for a limited set of recurrent paths in each case. In Section 5, we will argue that the attested diachronic sources reflect two different ways of constructing the plural set, through associativity in one case and similarity in the other, which in turn are related to the inherent semantic properties of the nouns involved in the formation of these two constructions. Some final remarks follow in Section 6. 


\section{Heterogeneous plurals: associativity and similarity}

According to Daniel and Moravcsik (2013), associative plural constructions are linguistic strategies consisting of a noun X plus some linguistic material (affix or independent marker), whose meaning is ' $\mathrm{X}$ and other people associated to $\mathrm{X}$ '. Corbett (2000: 101) calls 'associative plurals' the forms consisting of a nominal plus a marker and denoting 'a set comprised of the referent of the nominal (the main member) plus one or more associated members'. Associative plurals are generally limited to a subset of nouns with human reference, namely proper names and kin terms (see examples (1)-(2)):

(1) Dupaningan Agta $^{1}$ (Greater Central Philippine; Robinson 2008: 92)

$\begin{array}{lll}\text { na-bannag=dan } & \text { di } & \text { botay }=k o \\ \text { ADJ-tired=already } & \text { ASS.PL } & \text { uncle=1SG.GEN }\end{array}$

'My uncle and his companions are tired'

(2) Hup (Nadahup; Epps 2008: 206)

\begin{tabular}{|c|c|c|}
\hline Pána-ănd'วh & híd-ăn & g’วp-ว่h \\
\hline Ana-ASS.PL & 3PL-OBJ & scoop-DECL \\
\hline
\end{tabular}

Associative plurals differ from ordinary plurals in one crucial respect. An ordinary plural (e.g. chairs) construes a set of 2 or more elements as homogeneous, i.e. each member of the set is a token of the type referred to by the nominal base (i.e. chair). An associative plural, on the contrary, construes a set of $>2$ elements as a heterogeneous group centered on a focal element $X$ (the referent of the base): as a result, the set members cannot be considered X (e.g. Pána-ănd'ah in (2) does not include many individuals named Ana, but persons with different names). In other words, ordinary plurals construe the set through an operation of addition, while associative plurals require an operation of association with the noun X. As a consequence, while in ordinary plurals the set is independent from the context, the set resulting from an associative plural depends on the specific relation that $\mathrm{X}$ entertains with the other set members, and this relation is context-dependent (e.g. Pâna-ănd'ah in (2) may also be used to refer to 'Ana and her relatives' or 'Ana and her friends'; cf. Mauri and Sansò 2018).

According to Corbett (2000: 110-111), there is structural evidence in favor of a separation between ordinary plurals and associative plurals, with associative

1 Glottolog codes of all languages cited are listed in Appendix 1. 
plurals expressing a different category from number, namely associativity. One reason to consider associativity as a category different from number is that 'the associative meaning fits equally with dual and plural' (Corbett 2000: 108), ${ }^{2}$ and thus it is likely to constitute a dimension separate from (and orthogonal to) number. The separateness of plural number and associativity does not mean that the two categories are unrelated: though constituting an independent category, associativity always implies the construction of (and reference to) a plural set, as argued by Mauri and Sansò (2018), who discuss associative plurals within the larger picture of ad hoc categorization, a process different from pluralization and consisting in the construction of a set starting from some contextually relevant entity. The diachronic connection between ordinary and associative plurals that will be discussed below (Section 5) also speaks in favor of the conceptual relatedness between associativity and number.

In this paper, we will adopt the term 'associative plural' mostly because it is an established term in the literature, and because of the diachronic relationship between associative plurals and ordinary plurals that will be discussed below. However, this by no means implies that we consider associative plurals as a type of plural number.

Daniel and Moravcsik (2013) identify another strategy that they label similative plurals, namely constructions consisting of a noun X plus some other linguistic material (an affix or an independent marker), whose meaning is ' $\mathrm{X}$ and similar stuff'. Similative plurals are typically employed with inanimate and non-human nouns. An example is provided in (3):

(3) Udi (Nakh-Daghestanian, Lezgic; Ganenkov et al. 2010: 111)

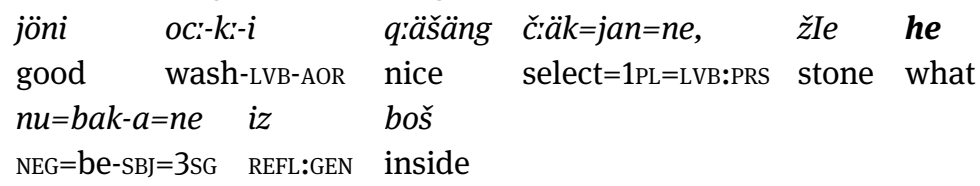

'We wash it thoroughly, sort it out, so that stones and the like will not appear inside of it.'

In (3), the noun žIe 'stone' is followed by he, glossed as 'what'. When he follows a noun $\mathrm{X}$, it widens the reference to items that are similar to the noun, denoting a larger heterogeneous set with the meaning ' $\mathrm{X}$ and the like'.

Compared with associative plurals, similative plurals have received less attention in the typological literature. Corbett (2000) does not even mention them, either as a particular type of number or in the discussion of associative plurals.

2 In Central Alaskan Yup'ik, for instance, the associative plural is cunankut, 'Chuna and his friends', while the associative dual is cunankuk, 'Chuna and his friend' (Corbett 2000: 108). 
Such a lack of attention can be explained as either the result of a lack of descriptive awareness, or of the low frequency of similative plurals across languages. Although the two factors are intertwined, it is in our view more likely that similative plurals, as defined by Daniel and Moravcsik (2013), are not rare, but simply rarely recognized as such.

What Daniel and Moravcsik (2013) call similative plural is functionally equivalent to what in pragmatics has been called general extender (Overstreet 1999). General extenders are elements like etcetera, and so on, and stuff, which either extend a given list so as to include further non-specific items (e.g. X, Y, etcetera) or open a potential list when they follow just one item (e.g. X etcetera). The existing literature on general extenders is mainly based on English and other European languages, and shows great terminological variation. ${ }^{3}$ According to Overstreet (1999:11), general extenders 'combine with a named exemplar (or exemplars) [...] some non-specific form of reference'. The languages whose general extenders have been examined in depth typically have analytic strategies (e.g. and so on), and this has probably prevented scholars from using the term plural to refer to these strategies, despite their ability to construe reference to a plural set. However, there is no functional difference between the Udi expression žle he in example (3) and its English translation 'stones and the like', where the general extender and the like is employed. Structurally, he in Udi is a synthetic expression, deriving from the interrogative pronoun 'what', while in English we have a sequence of a connective (and), the deictic manner adverb so and the adverb on. If we replace and so on by etcetera, we are left with a synthetic expression which is structurally not different from the one in Udi.

General extenders are almost systematically ignored by descriptive grammars, although they appear to be widely attested across languages. Example (4) provides an exception to this generalization: Konnerth (2014: 575-578), discussing a strategy attested in Karbi with the meaning ' $\mathrm{N}$ and the like', uses the label general extender:

$$
\begin{aligned}
& \text { Karbi (Kuki-Chin; Konnerth 2014: 575ff.) } \\
& \text { a-dūk=pen ajât=pen } \\
& \text { POSS-dust=from GEN.EX=from } \\
& \text { 'from the dust and everything' }
\end{aligned}
$$

All in all, the reduced literature on similative plurals is in our view likely to be due to a descriptive gap, rather than to the low frequency of the phenomenon.

3 Just to name a few labels: Dubois (1993) calls them extension particles, Channell (1994) vague category identifiers, Overstreet (1999) general extenders. 
Our choice of using the label proposed by Daniel and Moravcsik (2013), instead of the concurrent terms used in pragmatics, focuses on the fact that these strategies too refer to a plurality of entities, just like associative and ordinary plurals, triggering plural agreement on verbs when required. Furthermore, in discussing them together, Daniel and Moravcsik correctly highlight the functional closeness between associative and similative plurals, which is instead never mentioned in the literature on general extenders. Nonetheless, as already discussed for associative plurals, this terminological choice does not imply that we consider similative plurals as a special type of plural number. Rather, we consider them as another strategy to construe a plural set.

While associative plurals require the identification of the proper name/kin term as the pivot of a set of associated persons, similative plurals identify the noun as an exemplar of a larger set of similar items. Unlike ordinary plurals (e.g. stones), which denote a homogeneous set of items each of which is a token of the type denoted by the noun (stone), similative plurals denote a heterogeneous set of items sharing some context-relevant property with the exemplar noun, and thus crucially rely on the hearer's ability to identify this property and to construe the set accordingly: stones and the like, for instance, may include 'stones, small pieces of wood, dust' if the category exemplified is [small things to be washed away], but it may include 'stones, shells, pearls' if the category denoted is [decorative small things] (cf. Mauri 2017; Mauri and Sansò 2018 for a discussion of the various operations to construct a set of entities other than simple addition).

To sum up, associative plurals and similative plurals show a number of differences in function, but they also share some fundamental properties that legitimize a joint analysis. Firstly, unlike ordinary plurals, they both construe the plural set as heterogeneous, which motivates our choice to subsume them under the overarching term heterogeneous plurals. Secondly, in both cases the plural set referred to is construed through processes different from simple addition. Thirdly, the correct interpretation of the reference of the resulting set crucially depends on context, requiring the selection of either the relevant property which makes the set members similar to each other (as in similative plurals) or the relevant relation which makes the set members associated to the pivot noun (as in associative plurals).

A further reason that legitimizes both a joint analysis of associative plurals and similative plurals and an analysis of these two constructions in relation to ordinary plurals is that associative plurals, similative plurals and ordinary plurals appear to be sensitive to the animacy hierarchy (Speech Act Participants $>$ Proper names $>$ Kin $>$ Human $>$ Animate $>$ Inanimate). Ordinary plural markers are generally sensitive to this hierarchy with regard to their optionality: in languages with nonobligatory plural marking, the higher a referent ranks on the hierarchy, the more 
likely is it to take plural marking (Corbett 2000: 70-75). As already suggested, associative plurals and similative plurals too target specific portions of this hierarchy with a close-to-complementary distribution, the former being generally restricted to proper names and kin terms, the latter to non-human and inanimate referents. In Section 5, we will propose an explanation for this apparent complementarity based on the diachronic sources of associative plurals and similative plurals, arguing that their sensitivity to animacy is just epiphenomenal, and that what plays a role in this distribution are the referential properties of nouns. Table 1 summarizes the features characterizing heterogeneous plurals as compared to ordinary plurals:

Table 1: Ordinary plurals vs. heterogeneous plurals.

\begin{tabular}{|c|c|c|c|}
\hline & \multirow{2}{*}{$\begin{array}{l}\text { Ordinary plurals } \\
\text { 'chairs', 'friends' }\end{array}$} & \multicolumn{2}{|c|}{ Heterogeneous plurals } \\
\hline & & $\begin{array}{l}\text { Associative plural } \\
\text { 'John and associates' }\end{array}$ & $\begin{array}{l}\text { Similative plural } \\
\text { 'chairs and the like' }\end{array}$ \\
\hline 1. Construction of the set & Homogeneous & Heterogeneous & Heterogeneous \\
\hline $\begin{array}{l}\text { 2. Operation necessary to } \\
\text { construe the set }\end{array}$ & Addition & Associativity & Similarity \\
\hline 3. Context dependency & Independent & Context-dependent & Context-dependent \\
\hline
\end{tabular}

Associative and similative plurals tend to be encoded by means of different strategies. Only in a few languages is the same construction used for both associative and similative plural functions. But before discussing their sources in detail, a few words about the sample and the methodology adopted are in order. It is to this task that we now turn.

\section{Sample and methodology}

We examined data from 110 languages in which an associative plural or a similative plural construction is attested. With respect to associative plurals, the languages in the sample were selected based on a single criterion, namely the existence of a dedicated associative plural strategy, different from the ordinary plural marker. This criterion excludes all the cases in which the associative plural is the same as the ordinary plural. Languages of this type constitute 104 out of 236 (44.07\%) in Daniel and Moravcsik's (2013) sample. Associative plurals identical to ordinary plurals thus appear to be, by and large, the most widespread type across languages. This exclusion, however, is not detrimental to the completeness of the present analysis, because we cannot be sure whether the use of ordinary plurals as 
associative plurals is indicative of a diachronic development from ordinary plural to associative plural or vice versa.

On the one hand, there are cases in which such a direction of change is uncontroversial. As an anonymous referee points out, for instance, in West African French the ordinary plural form (which in European French cannot have an associative plural reading) is commonly used as an associative plural as a result of contact with West African languages with plural markers lending themselves to both ordinary plural and associative plural readings: thus, ses maris in this variety of French may mean both 'her (many) husbands' and 'her (current) husband and his friends'. This is a clear case of replica grammaticalization, as defined by Heine and Kuteva (2003: 539). On the other hand, there is ample evidence for the reverse direction of change, i.e. for associative plurals evolving into ordinary plural markers: in various English-based creoles, for instance, the ordinary plural is formed by means of a strategy that is a typical source of associative plurals, as will be discussed below, namely the sequence formed by the conjunction and followed by the plural pronoun them (e.g. Trinidad English Creole [not a sample language] $d i$ dog an dem, 'the dogs', di book an dem, 'the books', cf. Mühleisen 2013). Moreover, in various language families there is an 'animacy bias' (Cobbinah and Lüpke 2014: 212) whereby the spread of plural morphology proceeds along the animacy hierarchy from the top to the bottom, i.e. morphemes that originally attach to proper names/kin terms with a collective/associative semantics tend to increasingly combine with other animate/inanimate nouns, yielding ordinary (additive) plurals. These facts show that the diachronic connection between associative plurals and ordinary plurals is bidirectional. The scope of this article is limited to those cases in which there is clear directionality from a lexical/constructional source to associative plurals, which cannot always be determined when in a language the ordinary plural is also used with an associative plural reading.

As for similative plurals, the language sample has been built according to the same criterion, namely the existence of a dedicated similative plural marker/ construction. In this case too, there are languages where an ordinary plural marker is also used as a similative plural marker. Three such languages (Cavineña, Ese Ejja, and Kharia) have been included in the sample (see discussion in Section 4.2.3) because they show similative plural markers that are only optionally used as ordinary plural markers, and their source (an uncertainty marker) is sufficiently clear, suggesting a directionality from uncertainty marker to similative plural to (optional) ordinary plural (and not vice versa).

Diachronic information is explicitly available for a large portion of the languages included in the sample. Appendix 1 lists the languages in the sample, while Appendix 2 shows, for each language, the type of heterogeneous plural marker/construction attested, its possible diachronic source, the type of evidence 
we found in support of the hypothesis, and the status of the hypothesis (e.g. certain, likely or uncertain). Evidence for a given diachronic source is usually explicitly discussed by the author of the grammar, and may come from reconstruction (either language-internal or based on comparison with cognate languages), partial homophony, or identity between the source and the target. In some cases where diachronic information is not explicitly discussed, it was possible to reconstruct the source based on the internal analysis of the grammar or by comparison with related languages.

As to the different types of evidence for diachronic relatedness, it must be admitted that these do not show the same level of reliability. In particular, partial homophony between source and target may be accidental, especially in the case of short morphemes. A way to cope with such cases consists in monitoring to what extent (i) a given homophony pattern is recurrent across languages and (ii) the diachronic connection suggested by a given homophony pattern is corroborated by independent (and solid) pieces of evidence. On the contrary, when there is identity between source and target, the diachronic connection can be assumed on solid grounds, but a new problem arises: we may have to do with either (i) a case of polysemy of the source, whereby a given marker has various, context-dependent but related meanings, or (ii) a case of constructionalization, to be intended as the emergence and fixation of a new associative/similative plural construction (i.e. a conventionalized form-function pair) out of a less systematic morphosyntactic usage pattern. To provide just one example: if in a language the associative meaning is encoded by an affix or an independent word whose shape is identical to a lexical item meaning 'group', how shall we decide whether we consider this affix/independent word as an associative plural marker or as a lexical expression whose reference simply depends on the specific context (namely, the combination with a highly discourse-salient referent such as a proper name)? When diachronic data are scanty, as is the case with most languages of the sample, it is not always possible to make a decision. However, in some cases, which will be the object of specific discussion, there are reasons to assume that a process of constructionalization is taking or has taken place (e.g. when there is reduction of positional mobility of the source element, cf. Section 4.1.1).

This study is a diachronic-typological investigation. Diachronic typology aims to provide source-oriented explanations of language universals and synchronic tendencies, taking into account how the properties of the sources and the specific paths of change they follow determine the properties of the targets, which can be observed in synchrony. They differ from result-oriented explanations, which invoke functional factors such as efficiency, iconicity, etc. to explain typological patterns (Cristofaro 2017, 2019; Givón 1984, 1991; Sansò 2017, 2018, among others). Our aim is thus to provide source-oriented explanations for the variety of synchronic manifestations of 
heterogeneous plurals. In particular, we will show why some sources can evolve into both types of heterogeneous plurals, while others only give rise to one of the two types. We will cast light on both what associative plurals and similative plurals have in common, which motivates a joint analysis, but also on the different scenarios accounting for the developments from the sources to the two target constructions, tackling the question of what mechanisms foster the reinterpretation of the sources as associative plural or similative plural markers.

Finally, the identification of the sources of heterogeneous plurals will shed light on a crucial point discussed above, namely the relationship between them and ordinary plurals. All the sources that will be discussed below involve elements that are connected to two different operations of set construction, based on associative and similarity reasoning respectively. Some of these sources appear to be shared by ordinary plurals (cf. Section 5). Along with the possibility already mentioned above that associative plural and similative plural markers may evolve into ordinary plurals, this fact confirms that the two processes of set construction by means of associative or similarity-based reasoning are relevant to the domain of plurality, and thus further legitimizes an analysis of the two types of construction discussed within this larger domain.

\section{The diachronic sources of heterogeneous plurals}

\subsection{Associative plurals}

\subsubsection{Associative plurals from plural anaphoric elements (3PL pronouns/plural demonstratives)}

Various languages in the sample have associative plural markers that appear to be diachronically connected to 3PL pronouns. In what follows, we will survey a few of these languages, focusing on the type of evidence for this connection and hypothesizing some diachronic scenarios that account for the developments from 3PL pronouns to associative plural markers.

In some languages, associative plural markers are partially homophonous with 3PL pronouns. In Buwal, for instance, the associative plural morpheme $\bar{a} t \bar{a}$, which precedes the noun, is reminiscent in shape of the 3PL pronoun tātā: ${ }^{4}$

4 Also note that the 3rd person plural bound direct object marker in Buwal is - $\bar{a} t \bar{a}$ (Viljoen 2013: 275-276) 
(5) Buwal (Biu-Mandara; Viljoen 2013: 322)

$\begin{array}{lllll}\overline{\boldsymbol{a}} \boldsymbol{t} \overline{\boldsymbol{a}} & \text { martan } & \dot{e} j & \overline{\boldsymbol{a}} \boldsymbol{j} \overline{\boldsymbol{a}} & b a b a \\ \text { ASS.PL } & \text { Martin } & \text { and } & \text { ASS.PL } & \text { father }\end{array}$

'Martin and his associates and my father and his associates'

The associative plural morpheme mite in Nakanai is said to derive from the contraction of the conjunction me and the 3PL pronoun gite:

(6) Nakanai (Oceanic; Johnston 1980: 186)

$\begin{array}{lll}e & \text { Tubu } & \text { mite } \\ \text { NM } & \text { Tubu } & \text { ASS.PL }\end{array}$

'Tubu and the rest'

In other languages in the sample, there is identity between associative plural markers and 3PL pronouns. Two cases in point are Makary Kotoko and Mwotlap. In these languages, the associative plural construction consists in the juxtaposition of the proper name and the 3PL pronoun:

(7) Makary Kotoko (Biu-Mandara; Allison 2012: 107)

wo ro-ga en yá ró-n dó

village MOD:F-POSS 3PL mother MOD:F-POSS:2PL DET:F

'The village of your mother (and her people)'

(8) Mwotlap (Oceanic; François 2001: 385)

$\begin{array}{llll}\text { no } & \text { m-et } & \text { Maikol } & \boldsymbol{k e} \boldsymbol{y} \\ \text { 1SG } & \text { PERF-see } & \text { M. } & \text { 3PL }\end{array}$

'I met Michael and the others.'

The associative plural constructions exemplified in (7)-(8) are similar in structure to another type of construction, called inclusory construction and consisting in adjoining (in whatever order) a dual or plural pronoun (including a 3PL one), identifying the set of participants, with a name whose referent is included in the set of people denoted by the pronoun (Lichtenberk 2000: 2), as in (9)-(10):

(9) Lao (Kam-Tai; Enfield 2007: 82)

khaw3 qiø-kham2 paj3 saj3

3PL.B F.B-Kham go INDEF.PLACE

'Where did Kham and them go?'

(10) Toqabaqita (Oceanic; Lichtenberk 2000: 28-29)

$\begin{array}{lll}\text { tha } & \text { Gerea } & \text { kera } \\ \text { NM } & \text { G. } & \text { 3PL }\end{array}$

'Gerea 'n 'em' 
The free/bound pronominal forms in these constructions are called inclusory pronominals. These constructions, particularly frequent in Oceanic languages, diverge along two parameters, namely (i) whether or not the inclusory pronominal and the noun phrase form a phrase, and (ii) whether or not there is a marker signaling the set-subset relationship between the pronominal and the lexical noun phrase.

Lichtenberk (2000: 28ff.) argues that inclusory constructions are substantially different from associative plural constructions for two reasons:

(i) unlike associative plural constructions, which by definition refer to a group formed by the referent of a nominal plus other unidentified referents, inclusory constructions may also include other types of referents; example (11a) from Toqabaqita shows that the construction in (10) is also possible with 1st person dual pronouns;

(ii) unlike associative plural constructions, the two elements of an inclusory construction, i.e. the pronominal and the lexical noun phrase, can appear in whichever order, mostly depending on what referent is more salient (the individual vs. the group; cf. (11b), which is the reversal of (10)). Associative plural constructions, on the other hand, are characterized by a rigid order (either $\mathrm{N}+$ associative plural or associative plural $+\mathrm{N}$ ), and the referent of the lexical $\mathrm{NP}$ is pragmatically more salient than the associates.

(11) Toqabaqita (Lichtenberk 2000:29) brother-1SG 1DU(EXCL) 'my brother and I'
a. doqora-ku kamareqa
b. kera tha Gerea
3PL NM G.
'They, including Gerea'

Within the diachronic perspective adopted in this article, however, the differences between inclusory constructions and associative plural constructions cannot conceal the fact that at least some associative plural constructions in the sample may derive from the conventionalization or fixation of an inclusory construction. The following path can thus explain the associative plural constructions exemplified in (7) and (8):

(12) They PN/PN They (inclusory construction, no rigid order) > ASS.PL PN/PN ASS.PL (associative plural construction, rigid order)

This path implies a development from a less rigid strategy to refer to a group of people including a named individual, with no implications as to the relative 
prominence between the group and the individual (the inclusory construction), to a more fixed strategy to refer to a group of individuals revolving around a focal element (the associative plural construction). The manifestations of this development may be various: with regard to distribution, for instance, while inclusory constructions are generally possible with all types of pronouns (including 1PL and 2PL), associative plural constructions are limited to 3PL pronouns. Moreover, an associative plural construction may show signs of fixation/conventionalization that do not characterize inclusory constructions involving other plural or dual pronouns. In Makary Kotoko, for instance, en (3PL) can be juxtaposed to the proper name without any overt marker indicating the set-subset relationship, as in (7), or it may appear in combination with go 'with' before the focal referent: with 1PL exclusive pronouns, on the contrary, gó 'with' must be present, and the reduced version of the construction is not possible (cf. nē lū gó ló m só, 1PL:EXCL come with child your(F) DET:M, 'I came with your son' [lit. we came with your son], Allison 2012: 153). The Mwotlap construction is also possible with 3rd dual and trial pronouns, and with other dual pronouns (1st dual exclusive and 2nd person dual), but only when the 3PL pronoun kèy is involved is the order $\mathrm{N}+$ pronoun, whereas in all the other cases the two orders $(\mathrm{N}+$ pronoun/pronoun $+\mathrm{N})$ freely alternate (François 2001: 391). These facts suggest that in both Makary Kotoko and Mwotlap it is legitimate to consider the combinations of 3PL pronouns + proper name exemplified in (7) and (8) as not representing an occasional use of these pronouns to express an associative plural meaning. Rather, both combinations can be considered as constructions that have emerged out of less systematic patterns of usage.

Other cases discussed in this section seem to presuppose a different diachronic scenario, one in which the third person plural pronoun forms a coordinated noun phrase with the proper name:

$$
\text { PN and them }>\text { PN ASS.PL }
$$

This scenario accounts for the emergence of the Nakanai associative plural marker (mite < conjunction me + 3rd plural pronoun gite). Moreover, this is what happens in various English-based creoles, where the associative plural marker appears to derive from the combination of the conjunction and with them:

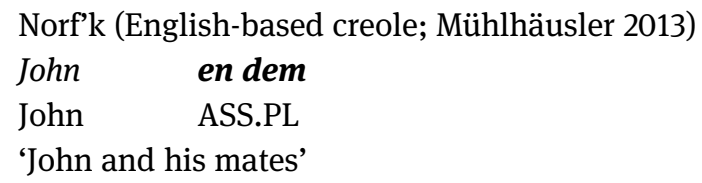

In other languages, there is similarity between associative plural markers and plural demonstratives. The associative plural prefix ann(ä)- in Amharic can be 
etymologically traced back to a demonstrative element (Gensler 2012: 281; cf. (15)), whereas in Kolyma Yukaghir the plural demonstrative taN-pe has a specific postnominal use with the meaning ' $\mathrm{X}$ and those associated with $\mathrm{X}$ ':

Amharic (Semitic; Leslau 1995: 177)

$\begin{array}{ll}\text { annä-ras } & \text { Yohannas } \\ \text { ASS.PL-Ras } & \text { Yohannes }\end{array}$

'Ras Yohannes and his followers'

(16) Kolyma Yukaghir (Yukaghir; Maslova 1999: 309)

qristos+taN-pe kebe-j-Ni

Christ+that-PL go-PFV-3PL:INTR

'Christ and his people left.'

These two cases suggest two possible diachronic scenarios through which demonstratives come to be reinterpreted as associative plural markers, schematized in (17a)-(17b) respectively:
a. Those (including) PN $>$ ASS.PL PN
b. PN (and) those $>$ PN ASS.PL

The scenarios in (17) substantially match the scenarios sketched in (12) and (13) for 3PL pronouns, and also in this case we can hypothesize a development from a less systematic strategy to deictically refer to a group of people known to the hearer to a more conventionalized way to encode associative plurality. The fact that in both Amharic and Kolyma Yukaghir the former demonstrative element has ended up being prefixed (as in (15)) or cliticized (as in (16)) to the proper name shows that the processes in (17) may manifest themselves as bona fide processes of grammaticalization, to be intended broadly as evolution of lexical or phrasal material into grammatical material (affixes or clitics).

Demonstratives are also a common source of 3PL pronouns (Heine and Kuteva 2002: 112-113). We therefore cannot rule out the possibility that the connection between demonstratives and associative plural markers is only indirect, and that an intermediate stage in which the demonstrative is used as a 3PL pronoun is necessary (plural demonstrative $>3 \mathrm{PL}$ pronoun $>$ associative plural marker). In Persian, for instance, the associative plural construction has the structure $\mathrm{N}+$ inã (e.g. Parviz inã , 'Parviz and his family or friends'): inã is a plural demonstrative that can also be used as a 3PL free pronoun (Mahootian and Gebhardt 1997: 93). Similarly, in Hdi the associative plural marker is i, preceding the noun: 
Hdi (Biu-Mandara; Frajzyngier and Shay 2002: 48)

$k a ̀$ vrà-gá-tá ì ngax ngax

SEQ return-INN-REF ASS.PL Ngah Ngah

'and Ngah Ngah and his people returned'

This marker has cognates in other Chadic languages, which are often employed as 3PL pronouns (Frajzyngier and Shay 2002: 47). In Gude (Biu-Mandara), for instance, the same prenominal $i$ (e.g. i Musa, 'Musa and others'; Frajzyngier 1997: 205) functions as both a plural demonstrative and a 3PL pronoun.

\subsubsection{Associative plurals from plural possessives}

In some languages of the sample the associative plural marker can be traced back to a plural possessive ('plural' referring to the number of possessed items). One of the possible scenarios leading from a plural possessive to an associative plural marker is instantiated by Lezgian. In this language there is a bimorphemic associative plural marker - $d$-bur, which comprises the reduced genitive form - $d$ and the plural substantivizer -bur. A literal translation of $-d$-bur would thus correspond to 'those [substantivized plural] of [genitive] X':

$$
\begin{aligned}
& \text { Lezgian (Lezgic; Haspelmath 1993: 79) } \\
& \text { Suna xala-d-bur.u-n } \quad k^{\prime} w a l \\
& \text { Suna aunt-GEN-SBST.PL-GEN house } \\
& \text { 'The house of Suna-xala and her family' }
\end{aligned}
$$

A similar scenario appears to account for Yaqui (Cahita), where the associative plural marker -taim is said to be decomposable into - $t a$, which marks the possessor NP in genitive phrases, and the pluralizer -im (Guerrero Valenzuela 2004: 16).

The Lezgian and Yaqui cases involve the combination of a substantivizer (i.e. a form that creates nouns) or a pluralizer with a name that designates the focal referent marked as possessor (the people belonging to $X$ ). In other languages, the diachronic scenario is different. For instance, in Nungon (Finisterre-Huon), the associative plural marker -nit is the result of the contraction of the plural possessive marker -ni with the comitative marker -ot (Sarvasy 2014: 199-200).

In still other languages there is identity between the associative plural marker and 3PL possessives. In Muna (Celebic; van der Berg 1989: 80), the associative plural marker is ndo. It appears in prenominal position in the associative plural construction, and is identical to a genitive marker encoding 3PL possession. The latter, however, is a suffix attached to the possessed noun (as in kambele-(n)do, shadow-3PL.POSS, 'their shadow', van den Berg 1989: 36), whereas the associative plural marker ndo appears before the pivot noun (van den Berg 1989: 80). 
Similarly, in Dupaningan Agta the associative plural marker di, called 'plural proper name marker' by Robinson (2008: 89) and preceding the pivot noun, is identical in form with the 3PL possessive marker di (cf. (20a) and (20b)), but the latter, unlike the former, appears after the possessed noun: ${ }^{5}$

(20) Dupaningan Agta (Greater Central Philippines; Robinson 2008: 84, 89)

a. $i \quad h a m a=d i \quad k e n$ hena $=d i$

DEF father=3PL.GEN and mother=3PL.GEN

'Their father and their mother'

b. di

Garwet

ASS.PL Garwet

'Garwet and his companions'

The data discussed in this section suggest the existence of various diachronic scenarios through which plural possessives come to be reinterpreted as associative plural markers. The abstract scenario in (21a), in particular, represents the development of Lezgian and Yaqui associative plural markers, whereas the path in (21b) accounts for the emergence of the Nungon construction:

a. $\mathrm{PN}-$ of + pluralizer/substantivizer ${ }^{6}>\mathrm{PN}-\mathrm{ASS} . \mathrm{PL}$

b. PN with (and) his ${ }_{[\mathrm{PL}]} /$ her $_{[\mathrm{PL}]}>\mathrm{PN}$ ASS.PL

Daniel (2004) argues that the scenario in (21a) implies structural and semantic modifications that qualify it as a constructionalization path in its own right. First, 'the referent of an associative plural form includes the referent of the stem [...], while the referent of a [...] plural possessive does not' (Daniel 2004: 398): in other words, a source construction such as those of Mary does not include Mary among its referents. Second, a plural possessive may be used to refer to any sort of possessed referents, including inanimate ones, and to any type of possession (legal ownership, etc.), while associative plurals necessarily refer to a set of human referents socially connected to the focal one. Third, the associative plural form resulting from the reinterpretation of a plural possessive may behave differently from its source from a morphosyntactic point of view: in Bulgarian, for instance, the plural possessive forms -ov-i (M.POSS-PL)/-in-i (F.POSS-PL) can combine with the postposed definite article only when they are used as possessives (Peš-ov-i-te, Pete-M.POSS-PL-DEF.PL, 'Pete's family (not including Pete)' vs. Peš-ov-i, PeteM.POSS-PL, 'Pete and his family/and the others'; cf. Daniel 2004: 390). An

5 In Ik, the associative plural is homophonous with the so-called 'possessive plurative' -InI-, a plural morpheme that also encodes possession (Schrock 2014: 164-165).

6 This formula is to be intended as the combination of a noun marked as possessor and a pluralizer/substantivizer. 
intermediate stage in this process of constructionalization, according to Daniel (2004: 400ff.), is the possibility of plural possessives such as those of Mary to be routinely interpreted as Mary's relatives/Mary's family, from which the interpretation Mary and his family/relatives is just a step away.

As for the development of the aforementioned Muna and Dupaningan Agta associative plural constructions, the different syntactic positions of the source and the target markers remain problematic in the absence of diachronic data and do not allow us to posit a clear diachronic scenario, although the connection with 3rd plural possessive markers appears to be clear.

\subsubsection{Associative plurals from nouns meaning 'group'/'family'/'people'/'house' and from universal quantifiers}

In this section, we deal with two sources whose original function is to refer to a whole set of people, namely nouns meaning 'group'/‘family'/'people'/'house' and universal quantifiers such as 'every'/'all'. The associative plural marker in Tuvaluan is saa. This is preposed to proper names, yielding the meaning of 'group of people whose representative member is X' (Besnier 2000: 364):

(22) Tuvaluan (Oceanic; Besnier 2000: 364)

$\begin{array}{llll}\text { saa } & \text { Sinaa } & \text { seki } & \text { mmai? } \\ \text { ASS.PL } & \text { Sina } & \text { NEG } & \text { come }\end{array}$

'Sina and her group haven’t come [back] yet?'

Saa can be traced back to the reconstructed Proto-Polynesian form *SAQA.2, whose reflexes in many daughter languages mean 'group' or 'family' (Greenhill and Clark 2011). Similarly, in Ma Manda, the associative plural is formed by combining the proper name with the independent word kadek (cf. (23a)), a word that also means 'group', as in (23b):

(23) Ma Manda (Finisterre-Huon; Pennington 2016: 249, 93) ${ }^{7}$
a. pandi kadek
PN group
'Pandi and his group'
b. sip ka-pape-baan kadek wa=lû
ship see.3SG-well-NMLZ group that=NOM
'The ship crew...' (lit. 'The ship-look-after ones')

\footnotetext{
7 The same marker can occasionally be juxtaposed to inanimate nouns, yielding a similative plural (e.g. mi kadek, 'water and such'; Pennington 2016: 250).
} 
A noun meaning 'group' has been reconstructed as the source of the Mandarin associative plural marker men by Iljic (2001: 94ff.). In various creole languages, moreover, there are associative plural morphemes deriving from such nouns (as in Kriol, where the associative plural marker is mob, cf. Schultze-Berndt and Angelo 2013). ${ }^{8}$

In another language of the sample, the associative plural marker originates from a universal quantifier meaning 'all, every'. This is the case of Sawila, in which the associative plural marker nanna/nang in one of its realizations is identical to the universal quantifier nanna 'all':

(24) Sawila (Kolana-Tanglapui; Kratochvíl 2014: 138-139, 134)
a. ni-ya
nanna
1SG-mother
ASS.PL
'my mother and her sisters'
b. ga-maddu nanna
3-child all
'all his children'

The diachronic scenarios behind the examples presented in this section have the structures in (25a)-(25b):
a. PN (and) group/family/house $>$ PN ASS.PL
b. PN (and) all > PN ASS.PL

Both sources are strategies to refer to the whole set of associates of the focal element. The case of Tuvaluan, in particular, is interesting because the source of the grammaticalization path is no longer attested as an independent lexeme, i.e. saa is only used as an associative plural marker, forming an inherently plural compound with the proper name. In other languages such as Ma Manda and Sawila, there are no elements to establish whether the words meaning 'group' or 'all' have grammaticalized (or are grammaticalizing) into associative plural markers.

\footnotetext{
8 Another language in which a noun meaning 'house' might be the source of the associative plural marker is Mehweb Dargwa (Lak-Dargwa; Chechuro 2015: 11), in which -qale (Abakar-qale, 'Abakar and his family') is partially homophonous with the noun qali 'house'. In Bilinarra (Western PamaNyungan), the associative plural morpheme is -nganyju (Meakins and Nordlinger 2013: 147). Meakins and Nordlinger (2013) do not provide an etymology for this marker, but in the related language Mudburra (not a sample language) the free form nganyju is glossed 'person' (cf. Bowern et al. no date). The associative plural in Tobelo (West Halmaheran) is formed by postposing wala to the proper name (Holton 2014: 88). Holton glosses wala as 'person', suggesting that this is the original meaning of this item. However, in the related language Sahu (not a sample language) wala is glossed 'house' (Visser and Voorhoeve 1987).
} 


\subsubsection{Associative plurals from 'and/with' and additive elements}

In various languages in the sample, the associative plural morpheme is identical to or can be traced back to an item whose primary function is noun phrase conjunction. Depending on the strategy the language adopts for NP conjunction, a coordinate vs. a comitative strategy (cf. Stassen 2000), the source of the associative plural marker can originally mean either 'and' or 'with'.

Various Oceanic languages in the sample (Belep, Hawaiian, Kiribati, Maori, Nelemwa), for instance, have associative plural morphemes that can be traced back to the Proto-Oceanic form ${ }^{\star}$ MA.4, whose reconstructed meaning is that of a noun phrase conjunction ('and/with') (Greenhill and Clark 2011). Compare the following Belep example:

\begin{tabular}{|c|c|c|}
\hline Belep (Oceanic; McCracker & 2012: 248) & \\
\hline$y a-m i d u=l a$ & pwemwa & Teâ Polo-ma \\
\hline DEM.LOC-DET.D.DH=LOC & village & Teâ Polo-ASS.PL \\
\hline
\end{tabular}

In Yidiny, the associative plural morpheme is - $b a$. Coordination of nouns (with human reference) within a noun phrase is also achieved through the addition of -ba to each one, as in (27b):

(27) Yidiny (Northern Pama-Nyungan; Dixon 1977: 416)
a. waguda-ba
gali- $\eta$
man-ASS.PL
go-PRS

'The man and other people are going.'
b. waguada-ba buna:-ba madi:nda- $\eta$ man-CONJ woman-CONJ walk_up.PRS
'The man and the woman are walking uphill.'

The diachronic scenario behind the associative plurals presented in this section possibly exploits the possibility of coordinators to be used with an enumerative function (cf. Stassen 2000: 5), as represented in (28).

(28) $\quad \mathrm{PN}$ and/with $\mathrm{X}>\mathrm{PN}$ and/with (enumerative conjunction) $>$ PN ASS.PL

It is not possible, however, to provide evidence for the steps of this scenario. In some of the languages discussed in this section, the conjunction can be repeated in lists with an enumerative function, a fact that is consistent with the intermediate stage hypothesized in (28): a case in point is Nêlêmwa, according to Bril (2011: 252). On the other hand, the marker $m a$ in Belep cannot be used to conjoin more than two NPs (McCracken 2012: 277), and maa in Maori no longer has any coordinating function (except in numerals from 11 to 20, Bauer 1993: 485ff.). As for the 
morphosyntactic manifestations of the diachronic scenario in (28), it must be noted that in Belep associative plural -ma is morphologically a suffix, while the homophonous NP linker ma forms a phrase with the second coordinand (McCracken 2012: 275ff.), which suggests a process of morphological fusion.

Two languages in the sample have associative plurals that can be traced back to an additive particle meaning 'also'. The two languages in question are Desano (ex. (29)) and Tariana (ex. (30)). The two languages are spoken very close to one another, leading Aikhenvald (2014: 50) to hypothesize that this might represent a semantic calque or an areal pattern.

(29) Desano (Tucanoan; Silva 2012: 170-171)

a. a?l-sã

dad-ASS.PL

'dad and the others'
b. pe-bu kudi-bu but- sa
walk-NON3.PERF hear-NON3.PERF I-ADD
'I also walked (and) heard (this story).'

(30) Tariana (Inland Northern Arawakan; Aikhenvald 2003: 633; Aikhenvald 2014: 45)
a. Marino-sini
Marino-ASS.PL
'Marino and his lot'
b. ina-sini kaya
woman(PL)-too so
'... and so [did] the women.'

Finally, there is one language in the sample in which the associative plural marker can be traced back to an accompaniment marker (encoding 'with' relations), but in which this marker does not also function as a NP coordinator: in Kayardild (Tangkic; Evans 1995: 155-156; 206), -nurru, which also encodes a transient or temporary relation between two entities (e.g. temporary location, transient possession), also functions as an associative plural marker. This case may be similar to those described in this section, but it cannot be excluded that the other meanings of -nurru are responsible for its development into an associative plural marker: both markers of possession (as discussed in Section 4.1.3) and markers of location (as will be discussed in the next section) may develop into associative plural markers. 


\subsubsection{Associative plurals from spatial expressions (close by, down)}

In this section we group together a few cases in which the possible source of the associative plural marker is a spatial expression. The associative plural morpheme mangka in Kuuk Thaayorre, exemplified in (31), is glossed 'low down by' by Gaby (2006: 605), ${ }^{9}$ who explains the diachronic connection between this spatial meaning and the target meaning as follows: 'it could be that the physical postures of being seated or supine are generally adopted only around friends and family'. Another possible (and less ad hoc) explanation is that the pivot of the construction (the proper name) is conceptualized as the upper point with respect to which his/ her associates are in a lower position.

(31) Kuuk Thaayorre (Northern Pama-Nyungan; Gaby 2006: 604-605)

\section{Dan mangka}

Dan low

'Dan mob' [i.e. Dan and the people associated with him]

In Central Asmat (Madang; Voorhoeve 1965: 335, 63), the associative plural morpheme is -mes (Sumuj-mes, 'Sumui and his family'); mes is also a formative meaning 'close by'/'along'. These two examples are semantically sufficiently clear to let us hypothesize that the possible diachronic scenarios accounting for them might have the shape in (32), but also too sporadic to allow us to sketch the steps of these paths: ${ }^{10}$
a. PN (and people) close by > PN ASS.PL
b. PN (and people) down/under (him/her) $>$ PN ASS.PL

\subsubsection{Associative plurals from collective markers}

In a few languages in the sample, associative plural markers are homophonous with collective markers, i.e. markers that are used to form nouns designating a collectivity of entities. In Abkhaz (Northwest Caucasian), the associative plural marker -raa is partially homophonous with a suffix -ra that combines with plant names to yield nouns of plantations (Hewitt 1979: 152), while in Buriat (Mongolic) the associative plural suffix -tan is the same suffix that is used to form collective

9 This morpheme is reconstructible as *mangka 'bottom' to Proto-Pama-Nyungan (Alpher 2004: 455).

10 Expressions consisting of a proper name and a spatial expression (e.g. $X$ e dintorni, lit. ' $\mathrm{X}$ and surroundings') are attested as discourse strategies to refer to ' $X$ and associated people' in languages that do not have a grammaticalized associative plural such as Italian (cf. Mauri and Sansò 2019). 
nouns from other nouns or adjectives (e.g. sasuu-tan 'people of the same age' < sasuu 'equal; cf. Poppe 1960: 88).

In Hup, the associative plural marker -ănd'əh can be decomposed into -an 'in direction/at place of' and =d'ah 'PLURAL' (Epps 2008: 206) (cf. example (2) in Section 2). Number marking in Hup is generally obligatory with human nouns only (Epps 2008: 192). The plural marker $=d$ 'วh also functions in some contexts as a collective marker, suggesting that this was the original function of this formative. This is particularly evident when $=d$ 'əh attaches to verb roots, yielding a meaning of 'group of people characterized by V' (e.g. Píd=d'əh, speak=PL 'those who speak the same language'; Epps 2008: 195, 227). The first segment of the associative plural marker in Hup, on the other hand, attaches to nominals yielding allative/locative meanings (Epps 2008: 181-182). Thus, the bimorphemic associative plural marker can be interpreted as 'the group of people at X's place'.11

\subsubsection{Other sources}

In this section, we group together some sources that are only sporadically represented in our sample. In order to postulate the existence of diachronic paths involving these sources, more data are needed. However, the paths leading from these sources to the target associative plural meaning are semantically quite plausible if compared with the paths discussed in Section 4.1.8.

In Zaar (East Chadic; Caron 2014: 304), the associative plural marker gjá: is identical to the plural of the quantifier 'some'. In Mian (Ok), the associative plural marker -wal is homophonous with one of the variants of the interrogative pronoun wan 'who' (Fedden 2007: 110ff.). Finally, a complex expression, modal-aad-avaru, combined with a proper name, is the way in which associative plurals are formed in Kannada (Southern Dravidian). This form consists of modal '(the first)' and an inflected form of the verb aagu 'become, function as, serve in a role'. The form

11 A similar case, but with no connections with collective morphology, is attested in Tswana (Bantoid), where the associative plural marker is bo- (bo-Kitso, 'Kitso and companions'). Creissels (2016: 34-35) draws a parallel between this form and another etymologically transparent construction with the meaning 'the people at X's place' ( $b a$ ga Kitso, 'the people of Kitso's place'). The structure $b a+g a+\mathrm{N}$ is formed by $b a$, 'the people of' (as in ba kgosi, 'the king's people'), and $g a$, 'the place of' (as in ga Kitso, 'at Kitso's'; Creissels 2016: 34). Both constructions can participate in an inclusory construction when combined with a further nominal element introduced by le: for instance, both bo-Kitso le Mpho and ba ga Kitso le Mpho mean 'they, Kitso and Mpho'. Based on this parallelism, Creissels (2016: 38) explains bo-, which cannot be the reflex of a reconstructed Bantu prefix because of its vocalism and tonal properties, as a coalescence of a former $b a+$ go-, the latter element being a locative prefix used with individual names, thus representing a former 'the people at X's place'. 
aadavaru 'those who became, functioned as...' consists of the past relative participle or adnominal form $a a-d-a$ and the third person human plural pronominal head -aru (from avaru 'those people'). The expression ' $\mathrm{X}$ modalaadavaru' thus seems to be a $\mathrm{N}+\mathrm{V}$ compound meaning 'those people (among whom) $\mathrm{X}$ is the first' (Sanford Steever, personal communication).

\subsubsection{Less certain paths}

In this section, we will deal with a few other less certain cases where there is homophony or identity between the associative plural and some other material that is attested in just one language of the sample, or in a couple of languages. These homophony/identity patterns may be suggestive of a diachronic relation between the associative plural and the homophonous/identical item, but the connection is problematic from the semantic point of view. The titles of the following subsections are thus necessarily speculative.

\subsubsection{Associative plurals from 'mother'?}

In Bargam there is homophony between the associative plural marker -nen and the base form of the word 'mother'. Hepner (2006: 58) hypothesizes that this homophony is based on the fact that 'the person named is the one responsible for the group associated with his or her name'. This is an isolated case in our sample, which does not allow us to draw any conclusion on the plausibility of a diachronic path connecting words meaning 'mother' to associative plurals:

(33) Bargam (Madang; Hepner 2006: 58, 61)
a. Anna-nen
kabiy-ab
ti-leh- $\varnothing$-iy.
name-ASS.PL garden-DAT PFV-go-PRS-NON1PL
'Anna and those with her went to the garden.'
b. Mat na anobun a-nen anobun nog.
man that face his-mother face SIM

'That man's face is like his mother's face.'

\subsubsection{Associative plurals from 2nd person plural pronouns?}

In a couple of unrelated languages in the sample, associative plural markers are identical to 2nd person plural pronouns. In Goemai, the associative plural marker gwén (cf. (34a)) is used to denote a unit comprising a single person and its associates. According to Hellwig (2011: 144), the associative plural probably originates from the pronoun gwen '2PL', exemplified in (35b). The context in which a 2nd person plural pronoun might have been reinterpreted as an associative plural is direct allocution in front of the addressees. When the speaker directly addresses 
his/her audience, he/she may use a second person pronoun in juxtaposition to a name to refer to a group of people, and in these cases gwén is in the same position as the associative plural, i.e. before the name, as in (34b).

(34) Goemai (West Chadic; Hellwig 2011: 143)
a. lù
gwén
Shályén
settlement:GEN
ASS.PL
$<$ NAME $>$
'the compound of Shalyen and his people.'
b. Só hèn=b'òòl gwén dàsk'óóm
so $1 \mathrm{SG} . \mathrm{SBJ}=$ appeal 2PL.OBJ elders
'So I ask you, elders...'

Hellwig (2011: 144) does not explain through what mechanisms a structure typical of direct allocution might have developed into a strategy to refer to groups of people associated with a single referent in other speech genres. However, the fact that the same homophony is found in Eastern Kayah Li (Karen; cf. Solnit 1997: 184), where $s \bar{\imath}$, besides being a 2nd person plural pronoun, is also used as a bound form meaning 'and company, and things like that' (i.e. as both an associative plural and a similative plural), might be corroborating such a hypothetical scenario.

\subsection{Similative plurals}

This section deals with the sources of similative plurals. Most of these sources are radically different from the sources of associative plurals. The implications of this differentiation for the semantics of the two types of plurals will be discussed in Section 5. In general, we can state that the similative plural constructions in our sample are etymologically more transparent than the associative plural constructions and their building blocks are more easily recognizable within the construction itself. ${ }^{12}$

12 An important type of similative plural formation found in our sample is partial reduplication or echo-reduplication. This type of reduplication involves the replacement of the first segment of the noun (e.g. the first consonant or the first syllable) with a fixed sequence of sounds. A case in point is Bengali saban-țaban, soap-RED, 'cleaning materials'/'soap and things like that' (Thompson 2012: 313). This kind of reduplication is generally a productive strategy used exclusively to convey the meaning ' $\mathrm{X}$ and similar things', which does not qualify it as a source of similative plurals stricto sensu: in other words, in these cases there is no diachronic evolution to be reconstructed from a source with a different meaning to a target associative plural construction. The reader is referred to Inkelas (2014), Stolz (2018), Mauri and Sansò (2018: 17-18) for a discussion of echo-reduplication. 


\subsubsection{Similative plurals from indefinite/interrogative elements or from elements meaning 'thing'}

Various languages in the sample have a similative plural historically derived from (and often still synchronically homophonous/identical to) an indefinite or an interrogative element. In Cupeño, for instance, the similative plural is formed by the indefinite element ishmi' $i$ 'something' preceding the noun:

$$
\begin{aligned}
& \text { Cupeño (California Uto-Aztecan; Hill 2005: 221) } \\
& \text { ivi-y ishmivi-y qingi-ch-i. } \\
& \text { this-OBJ something-OBJ squirrel-NPN-OBJ } \\
& \text { '[he used to kill] these squirrels and stuff.' }
\end{aligned}
$$

The fixed position of ishmi'i as a NP-internal modifier to the left of the nominal head is indicative of a completed process of constructionalization.

In Galo, similative plural constructions have the structure 'noun + jòò', where jòo is the interrogative pronoun 'what'. The status of jòo as a noun-phrase internal modifier is guaranteed by the fact that case enclitics such as =bá 'DAT' follow jòo and not the NP head (Post 2007: 346):

$$
\begin{aligned}
& \text { Galo (Tani; Post 2007: 345) } \\
& \text { acín dó-má lagàa=bá yunù [hibòk jòo]NP } \\
& \text { cooked.rice eat-NMLZ:ACMP reason=DAT 1.PL dam and/or.such } \\
& \text { anníi=go pó-là(a) } \\
& \text { bit=IND divert.water-NFIN } \\
& \text { 'In order to have something with our rice, we did a little dam-fishing and } \\
& \text { so on...' }
\end{aligned}
$$

Similarly, the Japanese similative plural marker -nado is said to derive from an originally interrogative form nani-to 'being what?' (Frellesvig 2010: 245), and in Nungon (Finisterre-Huon) the similative plural construction consists of the noun plus the interrogative element nungon 'what' (Sarvasy 2014: 538).

In still other languages, similative plural markers derive from elements meaning 'thing'. In Kuuk Thaayorre, the suffix =yuk 'STUFF' when added to a noun may be used to generalize its reference to include things normally associated with the denotatum of that noun. Etymologically, =yuk derives from the generic noun $y u k$, which denotes the class of trees and stick-like objects (e.g. cigarettes), but also a somewhat eclectic collection of (typically elongated) 'things': ${ }^{3}$

13 `yuku 'tree' can be reconstructed to Proto-Paman (cf. Hale 1964: 260). 
(37) Kuuk Thaayorre (Northern Pama-Nyungan; Gaby 2006: 209)

pormpr=yuk

house(ACC)=STUFF

'all the houses and things'

Elements meaning 'thing' may themselves be the source of interrogative/indefinite pronouns (Heine and Kuteva 2002: 295), and in some cases we are not able to tell whether it is the generic noun 'thing' that evolves into a similative plural marker or if there is an intermediate stage in which the generic noun has developed into an indefinite or interrogative element. In Karbi, for instance, the similative plural aját has grammaticalized from ját 'type, thing' - which also occurs as an indefinite pronoun - and the possessive $a$ - prefix (cf. ex. (4) in Section 2).

Ganenkov et al. (2010: 111ff.) argue that in Udi the use of interrogative and indefinite elements as similative plural markers (cf. example (3) in Section 2) originates in the conventionalization of their typical use as placeholders, i.e. as 'conventionalized lexical fillers which replace part of the syntactic structure due to production difficulties on the side of the speaker' (Ganenkov et al. 2010: 96). In particular, the placeholder takes on the function of a similative plural marker at the end of a list when the speaker fails (or simply does not want) to retrieve the last conjunct, but its position can also be before the noun, as the Cupeño example shows.

The scenario proposed by Ganenkov et al. (2010) can be schematized as follows:

indefinite/interrogative element/thing $>$ placeholder $>$ similative plural marker

The fixed position of the indefinite/interrogative/'thing' element in the examples discussed in this Section shows that the diachronic scenario in (38) can be qualified as a process of constructionalization.

\subsubsection{Similative plurals from 'and'}

In various languages of the sample, the similative plural marker is identical to a conjunction used to coordinate noun phrases. Martuthunira is a case in point. The conjunction -thurti conjoins nouns and is typically attached to both nominals in the conjoined expression. When attached to just one noun, it is used to extend its reference to cover things similar to the referent of that noun:

(39) Martuthunira (Western Pama-Nyungan; Dench 1994: 72)

$\begin{array}{lll}\text { ngayu-rru } \quad[\ldots] & \begin{array}{l}\text { karntara-thurti-lu manta-lalha } \\ \text { sinew-CONJ-EFF bind-PST }\end{array}\end{array}$

'Now I [...] bound it up with sinew and stuff.' 
Similarly, in Koasati (Muskogean) the enumerative conjunction -o:t may be attached to just one noun (i.e. without a second coordinand) to yield the meaning 'N and things like that' (cf. Kimball 1991: 413), and the same is possible in Yongning Na with the conjunction la33:

(40) Yongning Na (Burmese-Lolo; Lidz 2010: 257)

$d z \varepsilon 33 \quad$ la33 $q^{h} a 33-y \gamma 13 \quad d z_{0}$ J3
money etc. lots $\quad$ EXIST
'(They) had a lot of money and such.'

The path 'conjunction > similative plural' exploits the enumerative function (Stassen 2000: 5) of conjunctions in lists, and thus it appears to be similar to the path discussed in Section 4.1.4.

\subsubsection{Similative plurals from vagueness/uncertainty markers?}

Similative plural markers in some languages of the sample are identical to elements that also function as vagueness or uncertainty markers. In Tshangla, an NP marked with -te refers not only to what is exactly referred to by that NP but to similar stuff (choto-te, butter-PRT, 'butter and such', cf. Andvik 2010: 425). In lists, te may mark multiple NPs (choto-te gotham-te, butter-PRT egg-PRT, 'butter, egg, and things like that'). The same marker is also used as hedge in typically irrealis (e.g. future or conditional) contexts, as in (41):

Tshangla (Bodic; Andvik 2010: 426, 647)

changpu za-le-te gi-nyi-la, zakhang-ga di-le khe-le breakfast eat-INF-PRT COP-NF-PRT hotel-LOC go-INF must-INF

'If you want to eat breakfast, you must go to a hotel.'

Andvik (2010: 424ff.) implicitly states that the two functions of -te are related by treating them under the same rubric, but does not elaborate further on their relatedness. The fact that -te attaches to verbs in irrealis clauses might suggest that its original function was to mark uncertainty at the clausal level. All the verbs marked with -te, however, are nominalized forms, a fact that does not exclude that -te was originally a nominal hedge, and its uses in irrealis clauses are secondary. This fact makes any assumption about the directionality of change rather unsafe in this case. In other languages of the sample, however, there appear to be markers that at the same time mark the proposition as vague/uncertain and broaden the reference of the NP with which they combine. In Cavineña, for instance, the ordinary plural suffix -kwana is only optional, and when it combines with a noun, the resulting expression may be used with the function of a similative plural, as in 
(42a), where e-tima-kwana does not mean 'lower backs', but 'lower back and surrounding areas'. An identical phrasal particle $=k w a n a$, glossed UNCERT, is used when 'the speaker is uncertain of the reference/property/state/event/etc. expressed by a constituent' (Guillaume 2008: 692), as in (42b):

(42) Cavineña (Tacanan; Guillaume 2008: 482)

a. arepa karetu=tsewe jeti-wa=amabucha e-kwe even.though cart=ASS.PL come-PERF=even.though 1SG-GEN NPF-lower.back=PL uje-da

e-tima=kwana painful-ASF

'Even though I've traveled in the cart, my lower back ( ${ }^{\star}$ lower backs) area hurts.'

b. E-iya-u=kwana $=a m a=m i-r a=e k w a n a-j a$ ?

POT- $p$ ut $-\mathrm{POT}=\mathrm{UNCERT}=\mathrm{NEG}=2 \mathrm{SG}-\mathrm{ERG}=1 \mathrm{PL}-\mathrm{DAT}$

'Couldn't you leave (lit. put) it (your tape recorder) with us or something?'

Guillaume (2008: 484) states that there is a historical connection between the phrasal particle =kwana and the plural marker -kwana, although the semantic development is unclear. Two different paths can be hypothesized to account for this development:

(43) a. Vagueness/uncertainty marker $>$ ordinary plural $>$ similative plural

b. Vagueness/uncertainty marker $>$ similative plural $>$ ordinary plural

In the first scenario, a vagueness marker develops into an ordinary plural marker, which then comes to be used with a similative plural function with some nouns. In the second scenario, on the contrary, the vagueness marker combines with nouns to yield an approximation meaning ('or so'/'or something like that') when the speaker is not able to retrieve a more precise lexical item. The approximation function develops into a different function, namely that of extending the reference of a nominal item, when the speaker does not want to specify a set of items that are similar with or related to it ('or so' > 'and the like'). The inherent plurality of these expressions would be the bridgehead towards the development of the ordinary plural function. Both these scenarios are bound to remain quite speculative in the absence of diachronic data. Comparison with cognate languages adds further details to the picture: in Ese Ejja, a Tacanan language closely related to Cavineña, the plural marker =kwana may be used as a placeholder in lists (cf. (44)), but in addition to the (optional) ordinary plural and the similative plural function it is also used as an associative plural marker (Pao-kwana, 'Pablo and his family/other men', cf. Vuillermet 2012: 334-335). 
(44) Ese Ejja (Tacanan; Vuillermet 2012: 332)

kekwa-ka-ani-naje=pa, ebyo=jo neki akyana=kwana, pierce-3A-IPFV-PST=REP jungle=LOC stand.PRS things=PL ewí=kwana. bird_sp=PL

'He used to hunt (lit. pierce) what lives (lit. stands) in the jungle, various things, mutún birds.'

\subsubsection{Similative plurals from universal quantifiers}

In a couple of languages in the sample, the similative plural marker appears to be connected with universal quantifiers. In Diu Portuguese creole, for instance, the similative plural marker is tud, derived from Portuguese tudo 'everything' (Cardoso 2009: 176):

(45) Diu Portuguese Creole (Portuguese-based creole; Cardoso 2009: 176)

$\begin{array}{ll}\text { aros } & \text { tud } \\ \text { rice } & \text { SIM.PL }\end{array}$

'rice and all that'

In Yurakare, the similative plural marker is the complex expression a-mumuy dëpë glossed 'all of it completely' (van Gijn 2006: 210).

\section{Patterns of variation and diachrony}

In Section 4, we discussed the diachronic paths attested in our sample, which are summarized in Table 2. As the table shows, there are sources that only give rise to one type of heterogeneous plural and sources that may evolve into both types. The sources that are shared by associative plurals and similative plurals are 'and/with' connectives and universal quantifiers meaning 'all', while in all the other cases we observe different pathways leading to just one type of heterogeneous plural:

Table 2: Diachronic sources of associative and similative plurals.

\begin{tabular}{lll}
\hline Source & Associative plural markers & Similative plural markers \\
\hline 3PL pronoun & $\checkmark$ & \\
Plural demonstrative & $\checkmark$ & \\
Plural possessive & $\checkmark$ &
\end{tabular}


Table 2: (continued)

\begin{tabular}{lll}
\hline Source & Associative plural markers & Similative plural markers \\
\hline Spatial expression & $\checkmark$ & \\
'group'/'family'/'house' & $\checkmark$ & \\
Collective marker & $\checkmark$ & \\
Universal quantifier & $\checkmark$ & $\checkmark$ \\
'and/with', 'also' & $\checkmark$ & $\checkmark$ \\
'thing' & & $\checkmark$ \\
Indefinite pronoun & & $\checkmark$ \\
Interrogative marker & & $\checkmark$ \\
Vagueness/uncertainty marker & & \\
\hline
\end{tabular}

In our view, it is possible to group these sources in two macro-types, depending on the original function of the construction. On the one hand, many among the sources listed in Table 2 can be considered as 'set constructors', i.e. expressions that either directly refer to a set of individuals or are used in their original function to extend the reference of an item by means of operations such as addition to or saturation of the set. 3PL pronouns, plural demonstratives and plural possessives refer to sets of human referents, deictically anchoring them to the focal element (possessives) or to the speech context (3PL pronouns, plural demonstratives), while collective formatives and nouns meaning 'group'/'family' etc. are morphological and lexical resources to refer to a set of entities. Though not being strictly speaking set constructors, the spatial expressions that evolve into associative plural markers (see Section 4.1.5) have a deictic component that results in the spatial delimitation of the set: their original function is to denote a relation of closeness/adjacency to a focal element. Items such as 'and/with'/'also' are recruited as strategies to refer to a group of referents because their original function is conjunction and/or additivity, while universal quantifiers become sources of heterogeneous plurals by virtue of their referring to an entirety of referents, thus somehow saturating a potential set. On the other hand, other sources, and in particular those leading to similative plural markers, are connected to the domain of the speaker's low commitment to the exact reference of the set members: these include interrogative markers, indefinite pronouns, vagueness markers, and elements meaning 'thing'.

Similative plurals lie at the intersection of the two domains of set construction and low commitment/non-specificity: their function is to denote a set of nonspecific referents starting from a representative exemplar of the set and based on a contextually-determined property shared by all the members of the set. Evidence coming from the literature on general extenders (see Section 2) clearly shows that 
the nominal base in similative plurals is typically non-specific, frequently consisting in a bare noun (cf. Fiorentini 2018). Connected to the low referentiality of the nominal base is its role in the set construction: while in associative plurals the referent is the pivot (and thus hierarchically different from the other set members), in similative plurals the referent denoted by the noun is merely an exemplar, standing at the same level of all the other members of the set. Its reference is nonspecific because it is not introduced in discourse with an identificatory function, but rather with a descriptive one: the referent denoted by the nominal base of a similative plural has the function of pointing to some wider, higher-level set, of which it is representative. This function of similative plurals explains why only some types of set constructors (those that do not deictically refer to a group) and low commitment/vagueness markers are possible sources of this kind of heterogeneous plurals. In particular, in order to understand why vagueness/low commitment markers evolve into similative plural markers, we must take into account the speaker's aims when using similative plurals in discourse. Voghera (2012: 354-358) discusses general extenders as a way of communicating 'intentionally vague categories', arguing that there are situations in which speakers deliberately choose to be vague: in uttering ' $\mathrm{N}$ and the like', a speaker may acknowledge her lack of information regarding the other set elements, or she may hedge her commitment to the actual composition of the set. Moreover, speakers may experience production difficulties, which lead them to use placeholders instead of exact reference, resorting to interrogative and indefinite elements to indicate the existence of some non-specific larger set.

Associative plurals, on the other hand, denote contextually dependent sets of people associated with a focal element: the referents included in the set are known or at least easily identifiable by the hearer. In other words, the set is construed on the basis of a specific, context-dependent relation with the pivot, such that all further elements that can be ascribed to the set are humans in a specific relation with the pivot: in uttering John \& co, the speaker indeed relies on shared knowledge, allowing the addressee to unambiguously identify the relation between the set members and John (cf. Mauri and Sansò 2019). Through associative reasoning, an associative plural construction thus denotes a plural set that is always highly accessible: as Daniel (2020) puts is, associative plurals 'refer rather than describe'. This explains why the sources of associative plurals are limited to the first macrotype, namely set constructors.

Such a distribution of the attested diachronic patterns leads us back to the initial question, namely whether associative plurals and similative plurals should be considered as different phenomena or as different manifestations of the same overall phenomenon. As already argued in Section 2, associative plurals involve human referents, having mainly proper names or kin terms as nominal bases. 
These nominals are characterized by high referentiality and unique identity, as well as a high position on the animacy hierarchy (Anderson 2007: 99-100). The referent denoted by a proper name/kin term is typically highly identifiable for the interlocutors, and accessible in the discourse context. As argued by Anderson (2007: 170), proper names and kin terms have an identificatory rather than a descriptive function, i.e. they cannot be used to refer to a type, and act as 'referential anchors for discourse'. The high referentiality of these nouns triggers the construction of the plural set around a highly identifiable pivot, which is not only a set member, but above all the common denominator underlying membership to the set itself.

While associative plural constructions trigger the construction of a group of associated persons, similative plural constructions trigger the abstraction of a category, of which the nominal base is a representative exemplar. To correctly interpret a similative plural construction, speakers must follow a similarity-based reasoning, accessing context to identify the specific property of the noun that is shared by further potential exemplars of the category.

All in all, we may say that the low referentiality and non-specificity of the nominal base in similative plurals, which acts simply as an exemplar representative of a higher-level category, goes hand in hand with a low commitment by the speaker on the exact composition of the category. This is frequently conveyed through the speaker's expression of vagueness or uncertainty, leading to the reinterpretation of interrogative, indefinite and dubitative elements as similative plural markers.

Referentiality distinctions of the base, as well as the typical uses of the two types of heterogeneous plurals in discourse, are thus primary in explaining why some sources are recruited for only one type of heterogeneous plural, while others may evolve into both types. The apparent complementarity of associative plurals and similative plurals on the animacy hierarchy (see Section 2) is thus only epiphenomenal, as shown by the fact that, given the appropriate discourse conditions, associative plurals may be available down the animacy hierarchy and similative plurals may be available up the animacy hierarchy. Daniel (2020), for instance, mentions a case in Nganasan (Uralic, not a sample language) in which the plural form d'intz, 'bow', is used to designate 'bow and arrows', i.e. a focal object and other objects that are usually associated to it (and not 'bows and similar things'). A similar case, pointed out by an anonymous referee, is the Batad Ifugao prefix hin-, which marks a set of people centered around a focal individual (hin-ama, ASS.PL-father, 'father and children') and can also be prefixed to common nouns yielding the meaning 'the container and its content', as in hin-basu (ASS.PL-cup), 'a cup and its content' (Payne 1997: 99). A mechanism partly similar to the associative reasoning needed to construct the set denoted by an associative plural construction can thus be 
activated, though more rarely, also for focal elements that are not human. Similarly, as shown by Mauri (2017) and Magni (2018), proper names can be the nominal base of similative plural constructions if the context allows to identify a property that is shared by all the (non-human) members of the set. Various collective suffixes in Italian, for instance, can attach to proper names to convey a category of heterogeneous objects and situations that share with the named exemplar a given property: cases in point are formations such as berluscon-ame, 'Berlusconi-COLL', used to refer not necessarily to sets of people usually associated to Berlusconi (a former Prime Minister of the Italian Government), but to behaviors and situations that are typical of the named exemplar.

As also argued by Daniel (2020), proper names have uniqueness presumptions that make ways of pluralization other than additivity preferable for them, and this also explains, among other things, why associative plurals are widespread with proper names but rare with common human nouns. On the other hand, similative plural markers profile a semantic property of the base and expand it to a class (tigers and such $\rightarrow$ 'big predators'), and proper names usually do not provide a property to build a class upon. ${ }^{14}$

The diachronic patterns identified in our sample thus mirror the different processes and different discourse aims that lead to the construction of a heterogeneous plural set in associative plurals and similative plurals. Shall these differences lead us to consider associative plurals and similative plurals as different phenomena? In our opinion, the answer is negative. In both cases, we observe the construction of a heterogeneous plural set by means of a context-dependent process (an instance of ad hoc categorization, as discussed in Mauri and Sansò 2018), and the divergences described in this Section are direct consequences of the differences in the process leading to the construction of the set, which relies on association in associative plurals and on similarity in similative plurals.

Finally, as already mentioned, some sources of associative plurals and similative plurals are also attested as sources of ordinary plurals: the grammaticalization path 'all > PL', for instance, is attested in many varieties of English (cf. Kortmann and Schneider 2011: 274-276) and in other languages (the form buka 'all, together' is used as a plural marker in Waykumara [Central Pama-Nyungan, not a sample

14 Consistently with this characterization of associative plurals and similative plurals, it is worth noting that similative plurals from proper names are more frequent with family names of some culturally salient and visible figures, whereas with associative plurals first names are pivotal. First names are indexical ways of referring to individuals, bound by the specific speech situation, while family names are used to refer to people commonly known in a given culture: they are more likely to have some properties associated with them (e.g. greed, wealth, etc.) precisely by virtue of such notoriety, and these properties are the basis for the abstraction when they form a similative plural (we thank Michael Daniel for pointing out this to us). 
language]; cf. McDonald and Wurm 1979: 27); words meaning 'group, people' can evolve into ordinary plural markers (e.g. Seychelles Creole French [not a sample language] ban pirog, PL canoe, 'the canoes' < French bande, cf. Corne 1977: 34); 3PL pronouns too are attested as sources of ordinary plurals, as shown by the nominal plural marker mo in Mupun [West Chadic, not a sample language] (saar mo, hand PL, 'hands'), whose original function is that of a 3PL subject/object pronoun (Frajzyngier 1993: 160-162). These facts, and the fact that both associative plurals and similative plurals show diachronic connections (going in both directions) with ordinary plurals are sufficient reasons for considering heterogeneous plurals as manifestations of the domain of plurality, to be intended, from a wider perspective, as the functional domain of constructing (and referring to) sets of entities.

\section{Conclusions}

The aim of this paper was to provide a diachronic typology of associative and similative plurals, which have been discussed under the same overarching label of heterogeneous plurals. Based on a 110-language sample survey, we have argued that they can be considered as two manifestations of the same overall function, namely the construction of a (context-dependent) heterogeneous set.

We first defined the semantic features distinguishing associative from similative plurals, addressing their relation to ordinary plurals, and we then discussed and exemplified the diachronic patterns attested for the two construction types. While universal quantifiers and additive connectives are attested as sources for both associative and similative plurals, we found that most other sources only evolve into one of the two types.

This distribution can be explained on the basis of the referential properties characterizing the nominal bases typically found in the two types of heterogeneous plural, but also keeping into account the discourse contexts in which they are typically used: the interaction between a diachronic typological analysis and the examination of the patterns of use of constructions in discourse is thus conducive to a more thorough understanding of synchronic typological patterns and distributions.

\section{Abbreviations}

$\begin{array}{ll}\text { 1, 2,3 } & \text { 1st, } 2 \text { nd, 3rd person } \\ \text { I } & \text { noun class } \\ \text { A } & \text { agent }\end{array}$




\begin{tabular}{|c|c|}
\hline ACC & accusative \\
\hline ACMP & accompaniment \\
\hline ADD & additive \\
\hline ADJ & adjective marker \\
\hline AOR & aorist \\
\hline ASF & adjective suffix \\
\hline ASS.PL & associative plural \\
\hline B & bare \\
\hline CONJ & conjunction \\
\hline $\mathrm{COP}$ & copula \\
\hline D & deictic \\
\hline DAT & dative \\
\hline DECL & declarative marker \\
\hline DEF & definite marker \\
\hline DEM & demonstrative \\
\hline DET & determiner \\
\hline $\mathrm{DH}$ & downhill \\
\hline DU & dual \\
\hline EFF & effector \\
\hline ERG & ergative \\
\hline EXCL & exclusive \\
\hline EXIST & existential \\
\hline $\mathrm{F}$ & female/feminine \\
\hline GEN & genitive \\
\hline GEN.EX & general extender \\
\hline IND & individuator \\
\hline INDEF & indefinite \\
\hline INF & infinitive \\
\hline INN & movement to or from an inner space \\
\hline INTR & intransitive \\
\hline IPFV & imperfective \\
\hline LOC & locative \\
\hline M & masculine \\
\hline LVB & light verb \\
\hline MOD & non-noun modification marker \\
\hline NEG & negation \\
\hline NF & non-final verbal suffix \\
\hline NFIN & non-finite \\
\hline NM & noun marker \\
\hline NMLZ & nominalization \\
\hline NOM & nominative \\
\hline NON1 & non-first person \\
\hline NON3 & non-third person \\
\hline NOW & 'now' discourse clitic \\
\hline NPF & noun prefix \\
\hline NPN & non-possessed noun \\
\hline OBJ & object \\
\hline
\end{tabular}




$\begin{array}{ll}\text { PERF } & \text { perfect } \\ \text { PFV } & \text { perfective } \\ \text { PL } & \text { plural } \\ \text { PN } & \text { proper name } \\ \text { POSS } & \text { possessive } \\ \text { POT } & \text { potential } \\ \text { PRS } & \text { present } \\ \text { PRT } & \text { particle } \\ \text { PST } & \text { past } \\ \text { REF } & \text { referential } \\ \text { REFL } & \text { reflexive } \\ \text { REP } & \text { reportative } \\ \text { SBJ } & \text { subject } \\ \text { SBST } & \text { substantivizer } \\ \text { SG } & \text { singular } \\ \text { SIM } & \text { similative } \\ \text { UNCERT } & \text { uncertainty marker }\end{array}$

\section{References}

Aikhenvald, Alexandra Y. 2003. A grammar of Tariana, from Northwest Amazonia. Cambridge: Cambridge University Press.

Aikhenvald, Alexandra Y. 2014. Number and noun categorization. A view from north-west Amazonia. In Anne Storch \& Gerrit J. Dimmendaal (eds.), Number - Constructions and semantics. Case studies from Africa, Amazonia, India and Oceania, 33-55. Amsterdam: John Benjamins.

Allison, Sean David. 2012. Aspects of a grammar of Makary Kotoko (Chadic, Cameroon). University of Colorado. PhD Dissertation.

Alpher, Barry. 2004. Appendix 5.1. Proto-Pama-Nyungan Etyma. In Claire Bowern \& Harold Koch (eds.), Australian languages: Classification and the comparative method, 379-570.

Amsterdam: John Benjamins.

Anderson, John M. 2007. The grammar of names. Oxford: Oxford University Press.

Andvik, Erik E. 2010. A grammar of Tshangla. Leiden: Brill.

Bauer, Winifred. 1993. Maori. London: Routledge.

Besnier, Niko. 2000. Tuvaluan, a Polynesian language of the Central Pacific. London: Routledge. Bowern, Claire, Patience Epps, Jane Hill \& Patrick McConvell. No date. Hunter-Gatherer language database. https://huntergatherer.la.utexas.edu/ (accessed 12 May 2017).

Bril, Isabelle. 2011. AND and WITH conjunctive strategies in some Austronesian languages: Syntax, semantics, pragmatics. Language and Linguistics 12. 239-272.

Cardoso, Hugo C. 2009. The Indo-Portuguese language of Diu. University of Amsterdam. PhD Dissertation.

Caron, Bernard. 2014. Number in South-Bauchi West languages (Chadic, Nigeria). In Anne Storch \& Gerrit J. Dimmendaal (eds.), Number - Constructions and semantics. Case studies from Africa, Amazonia, India and Oceania, 283-308. Amsterdam: John Benjamins.

Channell, Joanna. 1994. Vague language. Oxford: Oxford University Press. 
Chechuro, Ilja Yu. 2015. Nominal morphology of Mehweb Dargwa. Working paper. Moscow: National Research University Higher School of Economics, Faculty of Humanities.

Cinque, Guglielmo. 2018. On the Merge position of additive and associative plurals. In Roberto Petrosino, Pietro Cerrone \& Harry van der Hulst (eds.), From sounds to structures: Beyond the veil of Maya, 495-509. Berlin: Mouton de Gruyter.

Cobbinah, Alexander Yao \& Friederike Lüpke. 2014. When number meets classification: The linguistic expression of number in Baïnounk languages. In Anne Storch \& Gerrit J. Dimmendaal (eds.), Number - Constructions and semantics: Case studies from Africa, Amazonia, India and Oceania, 199-220. Amsterdam: John Benjamins.

Corbett, Greville. 2000. Number. Cambridge: Cambridge University Press.

Corbett, Greville \& Marianne Mithun. 1996. Associative forms in a typology of number systems: Evidence from Yup'ik. Journal of Linguistics 32. 1-17.

Corne, Chris. 1977. Seychelles Creole grammar: Elements for Indian Ocean Proto-Creole reconstruction. Tübingen: Narr.

Creissels, Denis. 2016. Additive coordination, comitative adjunction, and associative plural in Tswana. Linguistique et Langues Africaines 2. 11-42.

Cristofaro, Sonia. 2017. Implicational universals and dependencies between grammatical phenomena. In Nick J. Enfield (ed.), Dependencies in language: On the causal ontology of linguistic systems, 1-24. Berlin: Language Science Press.

Cristofaro, Sonia. 2019. Taking diachronic evidence seriously. Result-oriented vs. source-oriented explanations of typological universals. In Karsten Schmidtke-Bode, Natalia Levshina, Susanne Michaelis \& Ilja A. Seržant (ed.), Explanation in typology: Diachronic sources, functional motivations and the nature of the evidence, 25-46. Berlin: Language Science Press.

Daniel, Mixail. 2004. From headless possessives to associative plurals. In Ji-jung Kim, Yuri Lander \& Barbara Hall Partee (eds.), Possessives and beyond: Syntax and semantics, 387-409. Amherst (MA): GLAS Publications.

Daniel, Michael. 2020. Associative plural as indexical category. Language Sciences 81.

Daniel, Michael \& Edith Moravcsik. 2013. The associative plural. In Matthew Dryer \& Martin Haspelmath (eds.), The world atlas of language structures online. Leipzig: Max Planck Institute for Evolutionary Anthropology. http://wals.info/chapter/36.

Dench, Alan Charles. 1994. Martuthunira: A language of the Pilbara region of Western Australia. Canberra: Pacific Linguistics.

Dixon, R. M. W. 1977. A grammar of Yidin. Cambridge: Cambridge University Press.

DuBois, Sylvie. 1993. Extension particles, etc. Language Variation and Change 4. 179-203.

Enfield, Nick. 2007. A grammar of Lao. Berlin: Mouton de Gruyter.

Epps, Patience. 2008. A grammar of Hup. Berlin: Mouton de Gruyter.

Evans, Nicholas. 1995. A grammar of Kayardild: With historical-comparative notes on Tangkic. Berlin: Mouton de Gruyter.

Fedden, O. Sebastian. 2007. A grammar of Mian: A Papuan language of New Guinea. Berlin: Mouton de Gruyter.

Fiorentini, Ilaria. 2018. Eccetera eccetera e così via di seguito. I general extenders dell'italiano contemporaneo. In Francesca Masini \& Fabio Tamburini (eds.), CLUB working papers in linguistics, vol. 2, 20-39. Bologna: CLUB - Circolo Linguistico dell'Università di Bologna.

Frajzyngier, Zygmunt. 1993. A grammar of Mupun. Berlin: Reimer.

Frajzyngier, Zygmunt. 1997. Grammaticalization of number: From demonstrative to nominal and verbal plural. Linguistic Typology 1. 193-224. 
Frajzyngier, Zygmunt \& Erin Shay. 2002. A grammar of Hdi. Berlin: Mouton de Gruyter.

François, Alex. 2001. Contraintes de structures et liberté dans l'organisation du discours: Une description du mwotlap, langue océanienne du Vanuatu. Université Paris IV: Sorbonne. Doctoral Dissertation.

Frellesvig, Bjarke. 2010. A history of the Japanese language. Cambridge: Cambridge University Press.

Gaby, Alice R. 2006. A grammar of Kuuk Thaayorre. The University of Melbourne. PhD Dissertation. Ganenkov, Dmitry, Yury Lander, \& Timur A. Maisak. 2010. From interrogatives to placeholders in Udi and Agul spontaneous narratives. In Nino Amiridze, Boyd Davis \& Margaret Maclagan (eds.), Fillers, pauses and placeholders, 95-118. Amsterdam: John Benjamins.

Gensler, Orin. 2012. Morphological typology of Semitic. In Stefan Weninger, in collaboration with Geoffrey Khan, Michael P. Streck \& Janet C. E. Watson (eds.), The Semitic languages: An international handbook, 279-302. Berlin: Mouton de Gruyter.

Givón, Talmy. 1984. Syntax: A functional-typological introduction, vol. 1. Amsterdam: John Benjamins.

Givón, Talmy. 1991. Syntax: A functional-typological introduction, vol. 2. Amsterdam: John Benjamins.

Greenhill, Simon J. \& Ross Clark. 2011. POLLEX-online: The Polynesian lexicon project online. Oceanic Linguistics 50: 551-559. https://pollex.shh.mpg.de.

Guerrero Valenzuela, Lilián G. 2004. The syntax-semantic interface in Yaqui complex sentences: $A$ role and reference grammar analysis. The State University of New York at Buffalo. PhD Dissertation.

Guillaume, Antoine. 2008. A grammar of Cavineña. Berlin: Mouton de Gruyter.

Hale, Kenneth. 1964. Classification of Northen Paman languages, Cape York Peninsula, Australia: A research report. Oceanic Linguistics 3. 248-265.

Haspelmath, Martin. 1993. A grammar of Lezgian. Berlin: Mouton di Gruyter.

Heine, Bernd \& Tania Kuteva. 2002. World lexicon of grammaticalization. Cambridge: Cambridge University Press.

Heine, Bernd \& Tania Kuteva. 2003. On contact-induced grammaticalization. Studies in Language 27. 529-72.

Hellwig, Birgit. 2011. A grammar of Goemai. Berlin: Mouton de Gruyter.

Hepner, Mark. 2006. Bargam grammar sketch. Summer Institute of Linguistics.

Hewitt, B. George. 1979. Abkhaz. Amsterdam: North-Holland.

Hill, Jane H. 2005. A grammar of Cupeño. Berkeley: University of California Press.

Holton, Gary. 2014. Numeral classifiers and number in two Papuan outliers of East Nusantara. In Marian Klamer \& František Kratochvíl (eds.), Number and quantity in East Nusantara, Papers from 12-ICAL, vol. 1, 79-102. Canberra: Australian National University.

Iljic, Robert. 2001. The origin of the suffix -men in Chinese. Bulletin of the School of Oriental and African Studies 64. 74-97.

Inkelas, Sharon. 2014. Non-concatenative derivation. Reduplication. In Rochelle Lieber \& Pavol Štekauer (eds.), The Oxford handbook of derivational morphology, 169-189. Oxford: Oxford University Press.

Johnston, Raymond L. 1980. Nakanai of New Britain: The grammar of an Oceanic language. Canberra: Pacific Linguistics.

Kimball, Geoffrey. 1991. Koasati grammar. Lincoln, Nebraska: University of Nebraska Press. Konnerth, Linda A. 2014. A grammar of Karbi. University of Oregon. PhD Dissertation. 
Kortmann, Bernd \& Agnes Schneider. 2011. Grammaticalization in non-standard varieties of English. In Heiko Narrog \& Bernd Heine (eds.), The Oxford handbook of grammaticalization, 263-278. Oxford: Oxford University Press.

Kratochvíl, František. 2014. Number in Abui and Sawila. In Marian Klamer (ed.), Number and quantity in East Nusantara, 123-151. Canberra: Pacific Linguistics.

Leslau, Wolf. 1995. Reference grammar of Amharic. Wiesbaden: Harrassowitz.

Lichtenberk, Frantisek. 2000. Inclusory pronominals. Oceanic Linguistics 39. 1-32.

Lidz, Liberty A. 2010. A descriptive grammar of Yongning Na (Mosuo). The University of Texas at Austin. PhD Dissertation.

Magni, Elisabetta. 2018. Collective suffixes and ad hoc categories: From Latin -ālia to Italian -aglia. Folia Linguistica Historica 39. 201-224.

Mahootian, Shahrzad \& Lewis Gebhardt. 1997. Persian. London: Routledge.

Maslova, Elena. 1999. A grammar of Kolyma Yukaghir. Berlin: Mouton de Gruyter.

Mauri, Caterina. 2017. Building and interpreting ad hoc categories: A linguistic analysis. In J. Blochowiak, C. Grisot, S. Durrleman-Tame \& C. Laenzlinger (eds.), Formal models in the study of language, 297-326. Berlin: Springer.

Mauri, Caterina \& Andrea Sansò. 2018. Linguistic strategies for ad hoc categorization: Theoretical assessment and cross-linguistic variation. Folia Linguistica Historica 39. 1-35.

Mauri, Caterina \& Andrea Sansò. 2019. Nouns \& co. Converging evidence in the analysis of associative plurals. STUF - Language Typology and Universals 72. 603-626.

McCracken, Chelsea Leigh. 2012. A grammar of Belep. Rice University. PhD Dissertation.

McDonald, M. \& Stephen A. Wurm. 1979. Basic materials in Wankumara (Galali): Grammar, sentences and vocabulary. Canberra: Australian National University.

Meakins, Felicity \& Rachel Nordlinger. 2013. A grammar of Bilinarra, an Australian aboriginal language of the Northern Territory. Berlin: Mouton de Gruyter.

Moravcsik, Edith. 2003. A semantic analysis of associative plurals. Studies in Language 27(3). 469-503.

Mühlhäusler, Peter. 2013. Norf'k. In Susanne M. Michaelis, Philippe Maurer, Martin Haspelmath \& Magnus Huber (eds.), Atlas of Pidgin and Creole language structures online. Leipzig: Max Planck Institute for Evolutionary Anthropology. http://apics-online.info/contributions/24 (accessed 11 May 2018).

Mühleisen, Susanne. 2013. Trinidad English Creole. In Susanne M. Michaelis, Philippe Maurer, Martin Haspelmath \& Magnus Huber (eds.), Atlas of Pidgin and Creole language structures online. Leipzig: Max Planck Institute for Evolutionary Anthropology. http://apics-online.info/ contributions/24 (accessed 11 May 2018).

Overstreet, Maryann. 1999. Whales, candlelight, and stuff like that: General extenders in English discourse. New York: Oxford University Press.

Payne, Thomas E. 1997. Describing morphosyntax: A guide for field linguists. Cambridge: Cambridge University Press.

Pennington, Ryan. 2016. A grammar of Ma Manda. A Papuan language of Morobe Province, Papua New Guinea. James Cook University. PhD Dissertation.

Poppe, Nicholas. 1960. Buriat grammar. Bloomington: Indiana University.

Post, Mark W. 2007. A grammar of Galo. La Trobe University. PhD Dissertation.

Robinson, Laura C. 2008. Dupaningan Agta: Grammar, vocabulary, and texts. University of Hawai'i. PhD Dissertation.

Sansò, Andrea. 2017. Where do antipassive constructions come from? A study in diachronic typology. Diachronica 34. 175-218. 
Sansò, Andrea. 2018. Explaining the diversity of antipassives: Formal grammar vs. (diachronic) typology. Language and Linguistics Compass 12. e12277.

Sarvasy, Hannah Sacha. 2014. A grammar of Nungon: A Papuan language of the Morobe province, Papua New Guinea. James Cook University. PhD Dissertation.

Schrock, Terrill B. 2014. The Ik language. Dictionary and grammar sketch. Berlin: Language Science Press.

Schultze-Berndt, Eva \& Denise Angelo. 2013. Kriol structure dataset. In Susanne M. Michaelis, Philippe Maurer, Martin Haspelmath \& Magnus Huber (eds.), Atlas of Pidgin and Creole language structures online. Leipzig: Max Planck Institute for Evolutionary Anthropology. http://apics-online.info/contributions/25.

Silva, Wilson de Lima. 2012. A descriptive grammar of Desano. University of Utah. PhD Dissertation.

Solnit, David B. 1997. Eastern Kayah Li: Grammar, texts, glossary. Honolulu: University of Hawaii Press.

Stassen, Leon. 2000. AND-languages and WITH-languages. Linguistic Typology 4. 1-54.

Stolz, Thomas. 2018. (Non-)canonical reduplication. In Aina Urdze (ed.), Non-prototypical reduplication, 201-278. Berlin: Mouton de Gruyter.

Thompson, Hanne-Ruth. 2012. Bengali. Amsterdam: John Benjamins.

van den Berg, René. 1989. A grammar of the Muna language. Dordrecht: Foris.

van Gijn, Rik. 2006. A grammar of Yurakaré. Radboud University Nijmegen. PhD Dissertation.

Viljoen, Melanie Helen. 2013. A grammatical description of the Buwal language. La Trobe University. PhD Dissertation.

Visser, L. E. \& C. L. Voorhoeve. 1987. Sahu-Indonesian-English dictionary and Sahu grammar sketch. Dordrecht: Foris.

Voghera, Miriam. 2012. Chitarre, violino, banjo e cose del genere. In Anna Maria Thornton \& Miriam Voghera (eds.), Per Tullio De Mauro. Studi offerti dalle allieve in occasione del suo $80^{\circ}$ compleanno, 341-364. Roma: Aracne.

Voorhoeve, C. L. 1965. The Flamingo Bay dialect of the Asmat language. The Hague: M. Nijhoff. Vuillermet, Marine. 2012. A grammar of Ese Ejja, a Takanan language of the Bolivian Amazon. Université Lumière Lyon 2. Doctoral Dissertation.

Supplementary Material: The online version of this article offers supplementary material (https:// doi.org/10.1515/lingty-2021-2072). 